\title{
Analytical Methods and Finite Element Method Computation The dental - periodontal tissues response
}

\author{
CRISTINA BICA ${ }^{1}$, KRISZTINA MARTHA ${ }^{2 *}$, DORIN BICA ${ }^{3}$, DANIELA ESIANU ${ }^{1}$, MADALINA NICOLETA MATEI ${ }^{4}$ \\ IUniversity of Medicine and Pharmacy of Tirgu Mures, Faculty of Dental Medicine, Department of Pediatric Dentistry, $38 \mathrm{Gh}$. \\ Marinescu Str., 540139 Tirgu Mures, Romania \\ 2 University of Medicine and Pharmacy of Tirgu-Mures, Faculty of Dental Medicine, Department of Orthodontics, 38 Gh. \\ Marinescu Str., 540139 Tirgu Mures, Romania \\ ${ }^{3}$ Petru Maior University of Tirgu Mures, Faculty of Engineering, Electrical Engineering and Computers Department, N. Iorga 1, \\ 540088, Tirgu Mures, Romania \\ ${ }^{4}$ Dunarea de Jos University of Galati, Faculty of Medicine and Pharmacy, Department of Dentistry, 47 Domneasca Str., 800008, \\ Galati, Romania
}

\begin{abstract}
The study of the biomechanical behaviour of dental-periodontal structures during orthodontic movement has been carried out on the basis of the analysis of values of equivalentstress following Von Mises theory, of the stress after the direction of the $s$ vertical force, which constitutes the essential component of the Von Mises equivalent stress, as well as on the basis of registering the deformities on the tooth axis. The processes of implementation, modelling, calculation and interpretation, using FEM, involved the following steps: defining the geometry and the structure of the model under analysis; meshing the geometry of the structure; connecting the nodal elements; defining the limit conditions and restrictions; loading the created model with vertical forces of different intensities; solving the equation system, having as unknowns in the nodes the following: movement, tension, tension on the spatial coordinates, Von Mises stress. We simulated the orthodontic intrusion through the application of some vertical forces with differentintensities and on structures with alveolar bone loss. The tension values in the tooth axis vary in direct proportion to the level of resorption of the alveolar bone, but the decisive element is the numerical value of the applied force, and not the absorption level.
\end{abstract}

Keywords: Finite Element Method, orthodontic force, tension, deformation

The use of the Finite Element Method (FEM) for the quantitative and qualitative evaluation of biomechanical reactions which take place during orthodontic movements at the level of dental-periodontal structures constitutes a modern complementary, non-invasive analytical method $[1,2]$. Nowadays, the continuous development of computerised technologies allows us to simulate and interpret clinical phenomena with the help of computer systems [3, 4]. In orthodontics, the FEM applicability can be exploited in order to project the design of dentalperiodontal structures, taking their geometry into account; in order to simulate dental movements under the action of orthodontic forces with variable intensity, direction and application point; in order to assess, quantitatively and qualitatively, the tensions and deformations which occur at the level of the affected structures.

As response to the effect of orthodontic forces, at the level of dental-periodontal structures, negative tension areas (compression mechanical stress) and positive tension area (expanse mechanical stress) are induced and differently distributed, according to the resistance centre of the tooth, local anatomical factors (alveolar bone resorption), direction and point of force application.

The clinical association with a periodontal pathology of the type of reducing the height of the alveolar bone or its resorption is a frequently encountered situation among adult patients who require orthodontic treatment. Under such circumstances, the resistance and rotation centre of the tooth, as well as the orthodontic movement mechanisms, change. Therefore, a correct decision regarding an orthodontic treatment in such conditions, without the emergence of iatrogenic effects, requires an extremely thorough biomechanical analysis [5-9].

\section{Experimental part}

The study of the behaviour of dental-periodontal tissues was carried out following the analysis of the values of equivalent stress after Von Mises theory (tensions from three-dimensional space), of the tension after the direction of $s_{z}$ which constitutes the essential component of the Von Mises equivalent stress, as well as following the observation of deformations in the tooth axis.

The processes of implementation, modelling, calculation and interpretation, using FEM, involved the following stages:

Defining the geometry and the structure of the model under analysis, according to the identified mechanical properties and particularities. In this sense, we considered the anatomical position of the studied element, which corresponded, geometrically, to a sensible horizontal inclination $\left(5^{\circ}\right)$.

Meshing the geometry of the structure, starting from the physical nodes which thus led to the formation of the field under analysis in finite elements. The meshing process involved obtaining a model equivalent to the real configuration. We evaluated 11 significant planes, in order to study the behaviour of the tooth, fact which allowed us to carry out the qualitative evaluation and interpretation of the results.

Connecting (assembling the nodal elements), defining the limit conditions and restrictions. The number of the freedom levels of the FEM model is under restrictions (zero movement conditions).

Loading and forcing details: loading the model created with vertical forces of different intensities and simulation of the orthodontic intrusion movement.

*email: marthakriszti@yahoo.com, Phone: 0722836621 
Solving the equation system, having as nodal unknowns the following: movements, tensions, tensions on the spatial coordinates, Von Mises stress.

As regards the physical properties, all the materials of the MEF model were considered elastic and isotropic. The Poisson coefficient values ( $n$ ) and the Young model values (E) for the tooth, periodontal ligament and alveolar bone are reference values in the literature [10].

\section{Results and discussions}

Following the analysis of the distribution of Van Mises equivalenttension, of the tension after the direction of action of the force and of the deformation in the tooth axis, we highlighted the following phenomena:

The distribution of the Von Mises tension, within the periodontal ligament, is similar both in the tooth with 2 $\mathrm{mm}$ resorption and in the tooth with $4 \mathrm{~mm}$ resorption, for values of the vertical force of ingression $\mathrm{F}=1 \mathrm{~N} \div 3 \mathrm{~N}$. For a supraliminal value of the ingression force $\mathrm{F}=4 \mathrm{~N}$, a sudden increase of the tension values was observed (table1).

The distribution of the deformation in the tooth axis is similar, qualitatively, to the tooth with the same degree of resorption, but, quantitatively, the values increase as the value of the vertical force increases. The maximum deformations are observable in all the situations at the superior level of the crown - plane $(+10.5)$, and they decrease towards the apex, where minimal values can be registered -- plane (-13). The deformation values increase as the value of the vertical ingression force increases (fig. $1)$.

For $\mathrm{F}=1 \mathrm{~N}$, on the segment between the $(-8 \rightarrow 8)$ planes, the deformation distribution can be approximated as being constant, having the value of $\sim 2 \times 10^{-4} \mathrm{~mm}$. The interest areas are the $(+10.5 \rightarrow 8)$ and $(-8 \rightarrow-13)$ extreme planes, in which the variation rate of the movements becomes linear, with a progressively increasing slant, which highlights the strong effect of the force on the deformations in the extreme planes. In each of these planes, the mechanical response (change of deformation according to the section) becomes significant for both of the absorption levels (fig.1).

For $\mathrm{F}=3 \mathrm{~N}$, within the segment between the $(10.5 \rightarrow 8)$ and $(-8 \rightarrow-13)$ planes, the variation characteristic can be approximated as being exponential to the extreme variations at the superior level of the crown and at the level of the apex. In the intermediary segment, between the ($8 \rightarrow 8$ ) planes, the distribution of the mechanical response (deformations) can be approximated following a law of linear variation (linear dependence of the value of deformations according the manifestation plan) (fig.1).

The tension distribution in the tooth axis is similar, qualitatively, in the tooth with 2 or $4 \mathrm{~mm}$ resorption, regardless of the intensity of the force applied, the tension being predominantly negative (of the compression type). Quantitatively, we noticed maximum values of the tension at the superior level of the crown, then the tension values decrease, increasing again towards the apex afterwards, at this level appearing values close to those evidenced at the level of the crown (table 2, fig. 2).

For $\mathrm{F}=1 \mathrm{~N}$, within the segment between the $(8 \rightarrow-10)$ medial planes, the tension distribution can be considered as constant ( $\sigma=$ constant, $\Delta \sigma / \Delta S=0)$. In the extreme planes (the superior level of the crown and the apex), the variation law is linear-ascending at the superior level of the crown, and linear-descending in the vicinity of the apex (fig. 2).

For $\mathrm{F}=3 \mathrm{~N}$ in the intermediary segment, the variation law has the form of $\Delta \sigma / \Delta S=0, \sigma=$ constant, of values close to those produced at forces of different intensity $(F=1 N)$. In the extreme planes, the variation law is linear, with an increase angle $\Delta \sigma / \Delta S$ higherr and of positive sign $(\Delta \sigma /$ $\Delta S>0$ ). In the apical plane, the variation law is linear, with high $\Delta \sigma / \Delta S$ slant and of negative sign $(\Delta \sigma / \Delta S<0)$ (fig. 2).

The success of orthodontic treatments in the case of association with alveolar bone resorption depends on optimising the orthodontic force. In order to diminish the strain and the side effects of the orthodontic treatment, respectively, it is mandatory to apply orthodontic forces of

\begin{tabular}{|c|c|c|c|}
\hline \multirow[t]{2}{*}{$\begin{array}{l}\text { Intensity of } \\
\text { the force }\end{array}$} & \multirow[t]{2}{*}{ Resorption } & \multicolumn{2}{|c|}{$\begin{array}{c}\text { Maximum values of the equivalent Von } \\
\left.\text { Mises stress ( } \sigma_{e c h} \max \right)\end{array}$} \\
\hline & & Palatal surface & Labial surface \\
\hline $\mathrm{F}=1 \mathrm{~N}$ & $2 \div 4 \mathrm{~mm}$ & $0.340 \mathrm{~N} / \mathrm{mm}^{2}$ & $0.333 \mathrm{~N} / \mathrm{mm}^{2}$ \\
\hline $\mathrm{F}=3 \mathrm{~N}$ & $2 \div 4 \mathrm{~mm}$ & $0.336 \mathrm{~N} / \mathrm{mm}^{2}$ & $0.342 \mathrm{~N} / \mathrm{mm}^{2}$ \\
\hline $\mathrm{F}=4 \mathrm{~N}$ & $2 \div 4 \mathrm{~mm}$ & $1.344 \mathrm{~N} / \mathrm{mm}^{2}$ & $1.335 \mathrm{~N} / \mathrm{mm}^{2}$ \\
\hline
\end{tabular}

Table 1

DISTRIBUTION OF THE EQUIVALENT VON MISESTENSION

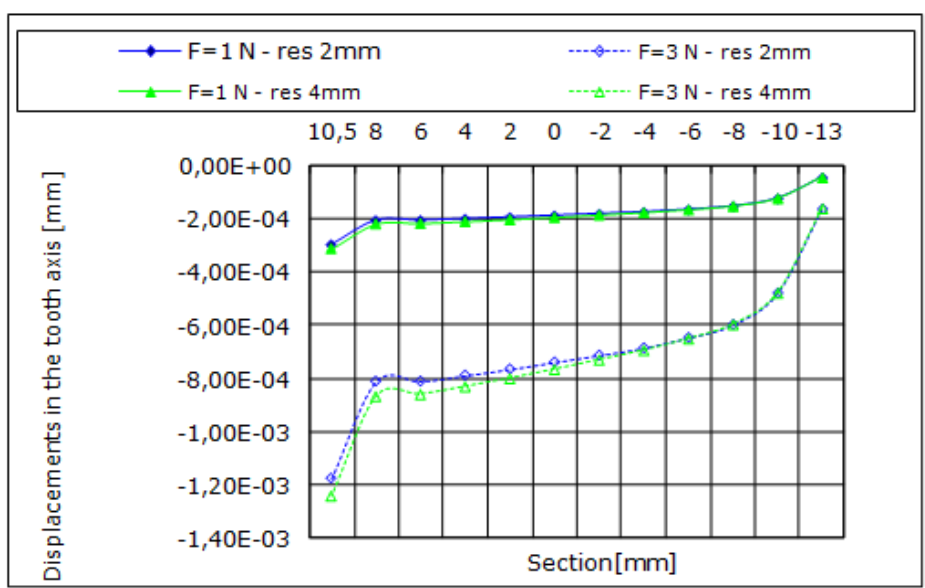




\begin{tabular}{|l|l|l|l|}
\hline Intensity of & Resorption & \multicolumn{2}{|l|}{ Maximum stress values $\left(\sigma_{\mathrm{y} \max }\right)$} \\
\cline { 3 - 4 } the force & & At the superior level of & At the level of the apex \\
& & the crown & \\
\hline $\mathrm{F}=1 \mathrm{~N}$ & & $-0.931 \div 0.955 \mathrm{~N} / \mathrm{mm}^{2}$ & $-0.689 \div 0.712 \mathrm{~N} / \mathrm{mm}^{2}$ \\
\hline $\mathrm{F}=3 \mathrm{~N}$ & $2 \div 4 \mathrm{~mm}$ & & $-2.675 \div 2.876 \mathrm{~N} / \mathrm{mm}^{2}$ \\
\hline
\end{tabular}

Table 2

TENSION DISTRIBUTION IN THE TOOTH AXIS

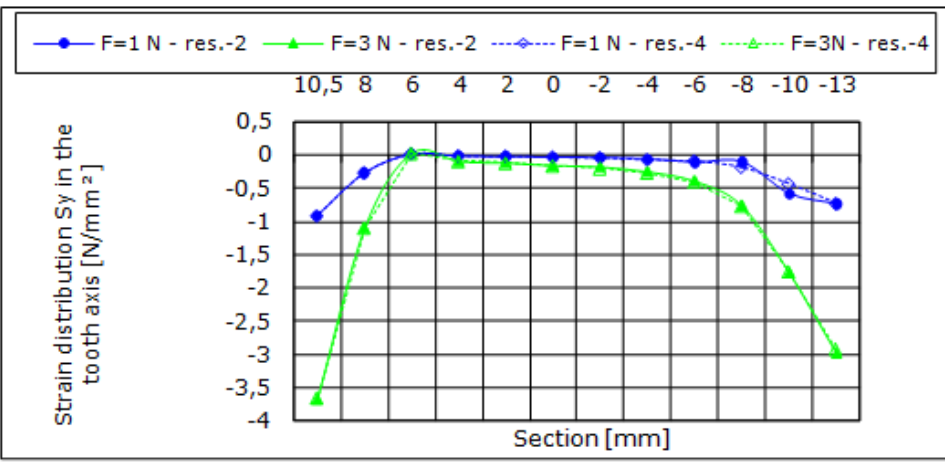

reduced intensity, which will allow bone remodelling and will limit the iatrogenic effects [11-13].

After an ample analysis which refers to clinical studies and experiments on animals regarding the biochemical reactions during orthodontic dental movements, a unanimously accepted conclusion could not be reached, one which could indicate the intensity and the optimal points of application of the orthodontic force in order to obtain the maximum efficiency in clinical orthodontics [14]. As a consequence, it is necessary to adapt and to orient the studies regarding the biomechanical reactions by using mathematical modelling methods, especially MEF [15]. This is a modern numerical analysis method, with an extremely varied applicability in technical fields (aeronautics, architecture, nuclear) and in the medical field as well, allowing a precise identification of stress under the influence of various external factors.

The tension after the direction of the orthodontic force increases along with the increase in the level of resorption of the alveolar bone. There are areas of maximum tensions in all the cases, regardless of the severity of the resorption level of the alveolar bone. With the help of MEF, it can be demonstrated that the alveolar bone resorption low ers the resistance centre of the tooth and changes the strain distribution at the level of the dental-periodontal structures.

Recent studies have quantified the orthodontic movement rate and the stress distribution through MEF, in adolescents and adults, comparatively. The starting point was that the periodontal tissue response varies greatly in adults, compared to adolescents, due to different vascularisation and cell population, which leads to a longer hyalinization period, therefore, to a longer treatment period in adults [10]. Moreover, the biochemical reactions in adults' periodontium, when compared to that of adolescents, might be due to different physical properties, especially to the Young elasticity module in the two age groups.

\section{Conclusions}

It is the numerical value of the applied vertical force that is decisive, and not the level of resorption. The linear/ constant variation of the movements registered in each plane, except for the extreme planes (the superior level of

the crown and the apex) manifests itself for any value of the force, thus suggesting a similar answer for this area.

The variation rate of the increase slant in the extreme planes is directly proportional with the value of the applied force intensity, from an approximately linear variation (for $F=1 N$ ) to an exponential one (for $F=3 N$ ), fact which suggests an extremely dynamic, even sudden mechanical response, once the forces with progressively increased intensity were applied.

A similar behaviour of the variation rate $\Delta \sigma / \Delta \mathrm{S}$ was observed at the superior level of the crown and in the apex, but it presented an opposite evolution.

The responsiveness of the tension values, in relation with the intermediary segment, is almost nought for any value of the applied force. The values of the tension in the tooth axis vary proportionally with the resorption level.

\section{References}

1.SINGH J .R., KAMBALYAL P., J AIN M., KHANDEKWAL P., Revolution in Orthodontics: Finite element analysis. J Int Soc Prev Community Dent, 2016; 6(2): 110-114.

2.FLORESCU, A., PANGICA, A.M., HANCU, V., MANU, R., BICLESANU, C.M., FEM Study Regarding Materials Retention Used for Abfraction Adhesive restoration. Mat.Plast, 53, no.4, 2016, p. 689

3.ANDRESSA M., PICCIONI R.V., CAMPOSE.A., CURYSAAD J.R., GALVAO M.R., RACHED A.A., Application of the Finite Element Method in Dentistry. RSBO, 2013; 10(4): 369-377.

4.RUDOLPH D.J., WILESM.G., SAMESHIMA G.T., A finite element model of apical force distribution from orthodontic tooth movement. Angle Orthodontist, 2001; 71:127-131.

5.MINCH L.E., SARUL M., NOWAK R., KAWALA B., ANTOSZEWSKASMITH J., Orthodontic intrusion of periodontally-compromised maxillary incisors: 3-dimensional finite element method analysis. Adv Clin Exp Med, 2017; 26(5): 829-833.

6.AGARWAL A., MAHAJAN S., VERMA S., BHARDWAJ P., SHARMA G., Evaluation of the Stress Induced in Tooth, Periodontal Ligament \& Alveolar Bone with Varying Degrees of Bone Loss During Various Types of Orthodontic Tooth Movements. J Clin Diagn Res, 2016; 10(2): ZC46-52.

7.ARUNA J., A study on evaluation of center of resistance of maxillary four incisors during simultaneous intrusion and retraction: A finite emenet study. J Pharm Bioallied Sci, 2014; 6(Suppl 1): S49-51. 
8. SCHMIDT F., GEIGER M.E., JÄGER R., LAPATKI B.G., Comparisonof methods to determine the center of resistance of teeth. Comput Methods Biomech Biomed Engin, 2016; 19(15): 1673-1682.

9.KETTENBEIL A., REIMAN S., REICHERT C., KEILIG L., JAGER A., BOURAUEL $C$., Numerical simulation and biomechanical analysis of an orthodontically treated periodontally damaged dentition. J Oofac Orthop, 2013; 74(6): 480-493.

10.TANNE K., YOSHIDA S., KAWATA T., SASAKI A., KNOX J., JONES M.L., An evaluation of the Biomecanical response of the Tooth and Periodontium to Orthodontic Forces in Adolescent and Adult Subject. British J Orthod, 1998; 25: 109-115.

11.MIZRAHI E., Risk management in clinical practice. Part 7. Dentolegal aspects of orthodontic practice. British Dental J, 2010; 209: 381390.
12.FRANKLIN E., Avoiding malpractice law suits: lessons learned from actual malpractice case histories. In Graber TM, Eliades T, Athanasiou AE. Risk management in orthodontics: experts' guide to malpractice. Chicago: Quintessence Publishing 2004.

13.HAN G., HUANG S., Root resorption after orthodontic Intrusion and Extrusion: an intraindividual study. Angle Orthodontist, 2004; 75: 741747.

14.REN Y., MALTHA J.C., KUIJPERS-J AGTMAN A.M., Otimum Force Magnitude for Orthodontic Tooth Movement: A Systematic Literature review. Angle Orthodontist, 2003; 73: 86-92.

15.DIACONU POPA, D., VITALARIU, A., TATARCIUC, M., MUNTEANU, F., Effect of Siver Nanoparticles Incorporation in Dental resins on Stress Distribution. Rev Chim.(Bucharest), 67, no.8, 2016,p.1571

$\overline{\text { Manuscript received: } 3.06 .2017}$ 